McElhinNy, M. W. 1964. Statistical significance of the fold test in paleomagnetism. Geophysical Journal of the Royal Astronomical Society, 8, pp. 338-340.

PoOLE, W. H. 1967. Tectonic evolution of Appalachian region of Canada. In Geology of the Atlantic region. Edited by E. R. W. Neale and H. Williams. The Geological Association of Canada, Special Paper No. 4, pp. 9-52.

RAO, K. V., and VAN DER Voo, R. 1979. Paleomagnetism of a Paleozoic anorthosite from the Appalachian Piedmont, northern Delaware: possible tectonic implications. Earth and Planetary Science Letters, 47, pp. 113-120.

Rao, K. V., Seguin, M. K., and Deutsch, E. R. 1981. Paleomagnetism of Siluro-Devonian and Cambrian granitic rocks from Avalon zone in Cape Breton Island, Nova Scotia. Canadian Journal of Earth Sciences, 18, pp. 1187-1210.

Reynolds, P. H., Zentilli, M., and Muecke, G. K. 1981. $\mathrm{K}-\mathrm{Ar}$ and ${ }^{40} \mathrm{Ar} r^{39} \mathrm{Ar}$ geochronology of granitoid rocks from southem Nova Scotia: Its bearing on the geological evolution of the Meguma Zone of the Appalachians. Canadian Journal of Earth Sciences, 18, pp. 386-394.

RoY, J. L., and ANDERSON, P. 1981. An investigation of the remanence characteristics of three sedimentary units of the Silurian Mascarene Group of New Brunswick, Canada. Journal of Geophysical Research, 86, pp. 6351-6368.

Roy, J. L., and MoRRIs, W. A. 1981. Paleomagnetic results from the Carboniferous of North America; the development of a chronostratigraphic marker horizon for Canadian east coast Carboniferous strata. Compte-Rendu, 9th International Congress of Carboniferous Stratigraphy and Geology. (In press.)

Roy, J. L., Anderson, P., and Lapointe, P. L. 1979. Paleomagnetic results from three rock units of New Brunswick and their bearing on the lower Paleozoic tectonics of North America. Canadian Journal of Earth Sciences, 16, pp. 1210-1227.

Schutts, L. D., Brecher, A., Hurley, P. M., MontGOMERY, C. W., and KRUEGER, H. W. 1976. A case study of the time and nature of paleomagnetic resetting in a mafic complex in New England. Canadian Journal of Earth Sciences, 13, pp. 898-907.

WATSON, G. S. 1956. Analysis of dispersion on a sphere. Monthly Notices of the Royal Astronomical Society, Geophysical Supplement, 7, pp. 153-159.

\title{
Paleomagnetism of Siluro-Devonian rocks from eastern Maine: ${ }^{1}$ Reply $^{2}$
}

\author{
Dennis V. Kent and Neil D. Opdyke \\ Lamont-Doherty Geological Observatory and Department of Geological Sciences of Columbia University, \\ Palisades, NY 10964, U.S.A.
}

Received August 17, 1981

Accepted August 25, 1981

Can. J. Earth Sci., 19, 232-237 (1982)

\section{Introduction}

Roy's discussion of our paper covers two topics. First, he attempts to show on the basis of various statistical tests that the characteristic magnetizations we reported in the Hersey red beds and the Eastport Formation were acquired after tectonic tilting and represent what he refers to as an "orogenic" remanence. Second, he presents an interpretation of paleomagnetic data from eastern Appalachian rock units proposing that low paleolatitudes are in general derived from orogenic remanences of Devonian-Carboniferous age whereas the intermediate to high paleolatitudes are derived from older remanences. In reply, we argue that Roy's

\footnotetext{
${ }^{1}$ Discussion by J. L. Roy. 1982. Canadian Journal of Earth Sciences, 19, pp. 225-232.

${ }^{2}$ Lamont-Doherty Geological Observatory Contribution No. 3232.
}

statistical methods may not be appropriate and nevertheless are not sufficient to demonstrate a post-folding origin of remanence and that the weight of evidence in fact favors remanence acquisition near the time of formation of the Siluro-Devonian rock units. Independent of the question of pre- or post-folding magnetization of these rock units, we find that the available paleomagnetic data from the eastern Appalachians do not support his model of a relatively simple paleolatitudinal progression with age for this area, but rather point to the results from Acadian (Devonian) intrusive rocks as anomalous for reasons that are not yet entirely clear.

\section{Age of magnetization}

Instead of analyzing the dispersion among the site means according to formation as we did, Roy first groups them according to six rock types. He then calculates that the dispersion among five of the rock type 
categories $(2 \mathrm{R}, 3 \mathrm{R}, 4 \mathrm{R}, 5 \mathrm{R}, 6 \mathrm{R}$, together constituting 20 of the 30 sites) is significantly less at a high confidence level before bedding tilt correction than after. From this he concludes that the magnetizations of these rocks are of post-tilting origin. The mean direction for rock type category $1 \mathrm{R}$, the Hersey sills (seven sites), was judged to belong to a different population than the other categories and was treated separately; the results of $\mathrm{N}$ a fold test on the Hersey sill sites remained inconclusive. $\mp$ Three sites with normal polarity were excluded from $\mp$ these statistical analyses because they gave directions not exactly antiparallel to those of the reversed sites.

The highly negative fold test obtained by Roy for the assembled rock types $(2 R, 3 R, 4 R, 5 R, 6 R)$ is largely $Z$ due to the equal weighting given to groups $4 R, 5 R$, and $\varangle 6 \mathrm{R}$, which consist of only two sites each. Although the questions of weighting and hierarchical level are long standing, unresolved problems in statistical analysis of paleomagnetic directions, we nevertheless point to other statistical considerations that suggest there may be some problems with Roy's technique. In conventional paleoA magnetic sampling, a site is typically characterized by E a particular bedding orientation, which will tend to vary Hetween sites but not within. For the purposes of a fold the site mean would therefore seem to be the proper ions: a fold test that is positive based on site means will tend to be made statistically indeterminate and an indeterminate test negative.

For these reasons, we consider our analysis by site means as more appropriate for testing the significance of change in dispersion with bedding tilt correction. We note that the dispersion does not change significantly with tilt correction using site means averaged by formation (Kent and Opdyke 1980), or by any of Roy's rock-type categories that are represented by more than two sites (1R, 2R and (or) $2 \mathrm{M}$, and $3 \mathrm{R}$ and (or) $3 \mathrm{M}$ ). Even the dispersion for the 20 site means in Roy's subset $(2 R, 3 R, 4 R, 5 R, 6 R)$, which when averaged by rock-type category give a highly negative fold test, is not significantly different before and after bedding tilt correction. We therefore maintain that the fold test on the Eastport and Hersey Formations is statistically indeterminate.

While a positive fold test can be considered strong evidence for the existence of a magnetization of pretilting origin, a statistically indeterminate (or even negative) fold test is not sufficient to demonstrate that the magnetizations were acquired after tilting. In fact, we concluded that, since the nature of the dispersion of the tilt-corrected characteristic site means for the Eastport and Hersey seemed to be consistent with the effects of apparent or real tectonic rotations about local vertical axes, these magnetizations are likely to be of pre-tilt origin. We observed, for example, that the tilt-corrected site means differ primarily in the declination component, whereas the inclinations are more uniform. This pattern of variation will produce a small-circle distribution of direction. To further illustrate this point, we plot in Fig. 1 the tilt-corrected paleomagnetic directions for the 20 sites constituting Roy's five groups ( $2 R$ to $6 R$ ). The distribution forms a small-circle segment whose center is near the sampling locale and is thus consistent with the local rotation hypothesis (MacDonald 1980).

There is also a fair chance that the distribution of tilt-corrected site means may not be Fisherian. Although the number of sites is not adequate for a definitive statement, a chi-square analysis (three degrees of freedom) indicates that whereas there is only a $25 \%$ probability that the uncorrected site mean distribution is non-Fisherian, the probability of a non-Fisherian distribution increases to $90 \%$ for the tilt-corrected directions. Application of a fold test, which assumes a comparison of Fisherian distributions, is therefore barely statistically valid for this set of data. If we hypothesize that the distribution was originally Fisherian and that only the declination components have been subsequently redistributed by net rotations about vertical axes, then it is possible to derive an estimate of the original precision parameter from the present distribution of inclinations alone by using the method of Kono (1980). For these 20 site means, corrected for tilt, we obtain a mean inclination of $38.2^{\circ}$, a value close to but lying between the arithmetic mean of $37.7^{\circ}$, which as expected underestimates the true mean inclination and the overestimate obtained by a Fisher mean, $39.2^{\circ}$. The estimate of the precision parameter is 64 , a value significantly 


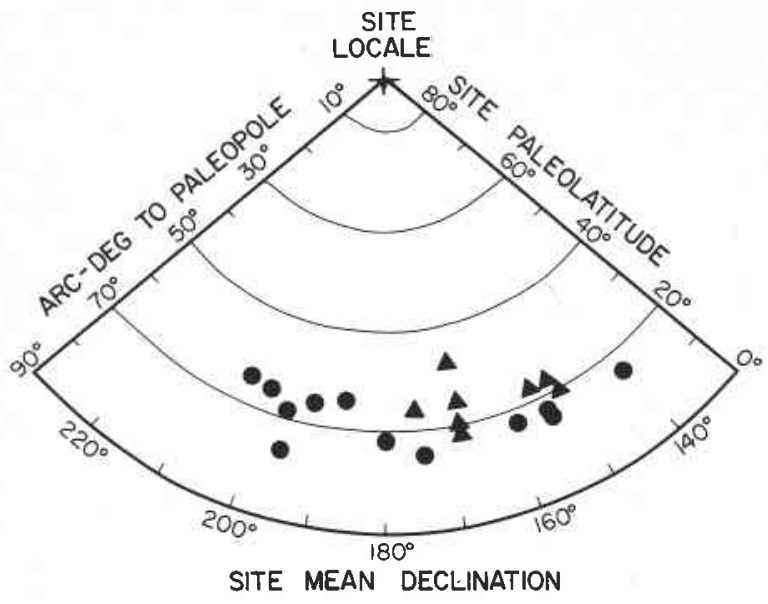

FIG. 1. Distribution of the 20 site mean characteristic paleomagnetic directions, after correction for local bedding tilts, that constitute rock type categories $2 \mathrm{R}$ (triangles), $3 \mathrm{R}$, $4 R, 5 R$, and 6R (circles) of Roy. For ease in distinguishing small-circle trends the directions are plotted on a polar projection after transformation of the sampling locale to the pole. The site mean directions appear to fall about a small-circle segment with a radius of approximately $70^{\circ}$ from the site locale, which corresponds to a paleolatitude of about $20^{\circ}$ for this region in the Siluro-Devonian.

greater than the estimate of 25 obtained from a conventional Fisher analysis and somewhat greater (although not significantly) than the value of 48 obtained by Fisher's method for the same site means before bedding tilt correction is applied.

Apparent tectonic rotation results when the tilt correction axis is assumed horizontal and the axis of net tectonic rotation is inclined, as in the case of a fold with plunge or when the strata have been tilted more than once about different horizontal axes. The effect on paleomagnetic directions is similar to that from actual tectonic rotation about a local vertical axis, both situations producing a smear in declinations. We discussed the geological evidence of both apparent and real tectonic rotation in the Eastport and Hersey Formations. The strata have experienced two stages of folding, post-Eastport and post-Perry (Late Devonian), and the numerous high-angle faults in the area may have produced actual block rotations about vertical axes. Either one or both of these structural features could account for the observed scatter in characteristic directions of pre-tilt origin, but at the same time effectively preclude the possibility of a positive fold test. A positive fold test in any case would only indicate the presence of a magnetization acquired before the last episode of rock deformation. In light of the post-Late Devonian tilting and faulting in the Eastport area, such a test would not in itself constrain the age of magnetization any more than
Roy would already concede (i.e., not later than Carboniferous).

Finally, despite Roy's statement to the contrary, the baked contact relations and the presence of both normal and reversed polarity provide relevant and supportive evidence for an early stage of magnetization acquisition because they are difficult to account for by a readily conceived remagnetization event. A regional thermal event, sufficient to reset the characteristic magnetizations with observed blocking temperatures up to $680^{\circ} \mathrm{C}$, would have very likely obscured the observed differences in magnetic properties between baked and unbaked red beds, as well as reset the directions at nearby sites to common polarity. A chemical event that could reset magnetizations in calcareous concretions, lavas, and red beds containing different magnetic mineralogies is also difficult to conceive. It was in consideration of possible remagnetization mechanisms that we drew attention to the similar characteristic directions obtained from rocks of various magnetic properties but of similar age. Although the absence of a plausible remagnetization mechanism alone is not compelling evidence that the Eastport and Hersey magnetizations are not secondary, it is nevertheless consistent with our other evidence in support of the hypothesis that the characteristic remanence in these rock units was acquired prior to tilting and possibly close to the time of their formation in the Siluro-Devonian.

\section{Paleopole analysis}

Whether the magnetizations of the Hersey red beds and Eastport Formation are of pre-tilt origin as we argue, or represent a post-tilt, "orogenic" remanence as Roy proposes, the question seems to be a relatively minor one in regard to Roy's simplest possible polar path (SPPP) analysis of eastern Appalachian paleopoles, particularly in the face of larger uncertainties and inconsistencies that are present in the data he uses to support his model.

We note, for example, that no supporting field evidence for initial magnetizations is documented for any rock units that according to Roy show paleolatitudes greater than for the tilt-corrected Hersey sills (pole $\mathrm{H}_{\mathrm{c}}$ ), about $-30^{\circ}$. The only positive fold test in his entire list of paleopoles is in Lapointe's (1979) study of 13 sites from the Wig Wam sandstone (pole 55) from the Botwood Group of Newfoundland. The Wig Wam is cited as Early Silurian and was presumably folded in the Devonian Acadian Orogeny; the tilt-corrected directions give a low paleolatitude of $-15^{\circ}$. Although a fold test was not possible, three sites from red rhyolites of the underlying Lawrenceton Formation (pole 54) give not very dissimilar directions after bedding tilt correction (paleolatitude of $-28^{\circ}$ ). 
Besides the previously discussed Hersey and Eastport, the only other study listed that includes supportive field evidence is on the Mississippi Valley-type sphalerite ore deposits and dolostone host rock in western Newfoundland (pole 33, Beales et al. 1974). The dolostone belongs to the St. George Group of Early Ordovician age and the epigenetic ore is thought to be genetically related to a pre-middle Ordovician erosion Surface. The similarity in paleopole positions obtained Ffor the ore and the host rock was interpreted to support the estimates of close timing between the deposition of the host limestone and of the ore. A corollary argument is that the stable magnetizations are likely to represent an Early to middle Ordovician paleofield, and indicate a paleolatitude of about $-15^{\circ}$. However, the inclusion of This study in Roy's eastern Appalachian paleopole list is Gcurious inasmuch as western Newfoundland is usually considered both from geological and paleomagnetic evidence as part of cratonic North America (e.g., Deutsch and Rao 1977). Indeed, pole 33 is consistent with other early Paleozoic paleomagnetic data from Gratonic North America, which indicate low paleolaticondes for its eastern margin, but it is certainly not ofmpatable with Roy's hypothesis of a simple age कुog gression of high to low paleolatitudes for the eastern A A palachians. Exclusion of this western Newfoundland Faleopole from consideration does not, however, signi乐依antly alter the general problem with Roy's model.

JFurther examination of the individual paleopoles used fo-construct Roy's SPPP reveals that the high $\left(>40^{\circ}\right)$ alateolatides all come from igneous intrusive rocks, for most of which it can be shown on the basis of moss-cutting relations, cooling ages, and geological etting that they cannot possess magnetizations that Todate the age of the rock units giving low paleolatiFudes of supposed orogenic origin. In Newfoundland, the Lawrenceton rhyolite $\left(-28^{\circ}\right)$ and the Wig Wam andstone $\left(-15^{\circ}\right)$ were folded, then intruded by the @Mount Peyton diorite (pole 56; paleolatitude of $-33^{\circ}$ ) and the Mount Peyton granite (pole 85), the youngest $=380 \mathrm{Ma}$ ) unit in this set but giving the highest aleolatitude $\left(-76^{\circ}\right)$. In the coastal volcanic belt of New Brunswick and Maine, the St. George (pole 82) and the St. Stephen (pole 80) plutons (paleolatitudes of -68 and $73^{\circ}$, respectively, although another direction from the St. George, pole 81 , gives a paleolatitude of only $-13^{\circ}$ ) are regarded as post-Acadian folding intrusions. In comparison, the older, pre-Acadian units of the Mascarene Group (giving poles $57, \mathrm{P}, \mathrm{Zh}, \mathrm{Zm}, \mathrm{C}\left(\mathrm{M}^{\mathrm{l}}\right)$, to which can be added the Hersey and Eastport poles) all indicate lower site paleolatitudes, in the range of -12 to $-45^{\circ}$. What is more, Roy and Anderson (1981) regard at least their pole $\mathrm{P}$ (paleolatitude of $-40^{\circ}$ ) as representative of the paleomagnetic field at the time of deposition of the Mascarene in the Silurian, a conclusion that is in better accord with our original paleolatitude estimate of about $-23^{\circ}$ for the somewhat younger Hersey and Eastport Formations than with the generally higher paleolatitudes for the still younger St. George and St. Stephen plutons, as far as his proposed age-dependent trend in paleolatitude is concerned.

Two other sets of results cited by Roy as giving high apparent paleolatitudes are worth brief discussion. Work on the Bonavista Bay dikes (pole 84, paleolatitude of $-75^{\circ}$ ) to our knowledge has not yet appeared in print. However, it is likely from their geological setting that the dikes are again post-Acadian, an inference supported by the age range of 380-410 Ma cited by Roy.

The geological setting and radiometric age information for the Cape Breton granites (poles CB2, CB1, $\mathrm{CB} 4, \mathrm{CB} 3$, giving site paleolatitudes of $-61,-53$, -48 , and $-12^{\circ}$, respectively) are referred by Rao et al. (1981) to the works of Wiebe (1972) and Cormier (1972). Although these reports suggest two different interpretations of the time of emplacement of the granites in the northern highlands of Cape Breton, both interpretations imply an age for the magnetization no older than the Acadian Orogeny. The radiometric age data suggest that either all of the granites are old (560 $\mathrm{Ma}$ ) but were later affected by the Acadian Orogeny in the Devonian, which led to an updating of biotite ages (Cormier 1972), or there are two generations of granites represented, an older set updated towards typical Acadian ages (360-400 Ma) and a younger set correlated with Devonian (Acadian) granites elsewhere in the northern Appalachians (Wiebe 1972). The time of acquisition of magnetization of the granites is therefore apparently constrained to be Acadian or younger, either by thermal resetting (e.g., York 1978) in the older granites or by primary cooling in any younger ones.

On the basis of these considerations, only the Arden pluton (pole AP, paleolatitude of $-55^{\circ}$ ) remains as a likely candidate to define the older (high paleolatitude) end of Roy's SPPP, assuming that the age of magnetization of the Cambrian Arden pluton is the age of the last metamorphism, at about 440 Ma (Late Ordovician; Rao and Van der Voo 1980). Rao and Van der Voo point out that the Arden paleopole deviates widely from available coeval poles from the North American craton and suggest an original association of the pluton and the surrounding Piedmont with the African plate. Whether the Delaware Piedmont is a southward continuation of the northern Appalachian displaced terrain is another interesting possibility that is difficult at present to confirm or deny. We note that the Arden pole is far removed from pole 33 (which, however, may be more representative of the North American craton in the Early Ordovician as discussed earlier) as well as a preliminary pole reported 
for the Lower Ordovician Wabana Group of eastern Newfoundland, which gives a near equatorial paleolatitude (Deutsch and Rao 1970).

Even if the Arden paleopole is applicable to the northern Appalachian displaced terrain, paleomagnetic results from the Wig Wam of the Botwood Group suggest that by pre-Acadian, possibly Early Silurian time, at least central Newfoundland already occupied lower paleolatitudes, a conclusion in accord with our interpretation of the data from the Eastport and Hersey Formations from eastern Maine. The magnetization of the Wig Wam cannot be easily discounted as an "orogenic" remanence because of the positive fold test. At the same time, the geological relationships do not allow the possibility that the high paleolatitude results from the Mount Peyton granite and diorite units, which intrude the folded Botwood Group, could represent a paleomagnetic field earlier than the Wig Wam or even of pre-Acadian folding age, as Roy's hypothesis would require.

The best available evidence therefore indicates that the paleopole position with respect to the eastern Appalachians was already by the Siluro-Devonian near its Late Devonian - Early Carboniferous position, the view we favored in the paper under discussion. We therefore regard the high paleolatitude results from the Acadian intrusive rocks, with either final cooling or emplacement times of probable Devonian age, as anomalous. The additional paleopole data on intrusions cited by Roy, not available to us earlier, serve only to reinforce this assessment. Their acceptance as records of a geocentric axial dipole field would imply a paleolatitude shift of as much as $120^{\circ}$ within the Devonian, from about -15 to $-30^{\circ}$ in the Siluro-Devonian (Wig Wam, Laurenceton, Eastport, Hersey Formations) to about $-75^{\circ}$ (Mount Peyton granite, St. Stephen pluton, Bonavista Bay dikes) then back again to about $-15^{\circ}$ by the end of the Devonian and the beginning of the Carboniferous (Roy 1972). Such a scenario implies a displacement rate in excess of $20 \mathrm{~cm} /$ year, a rate that strikes us as extraordinarily high and improbable.

Further reason to doubt the significance of the paleomagnetic data from the Acadian intrusive rocks for tectonic interpretation is the chaotic and inconsistent nature of rotations, both in magnitude and in sense, that is required to bring the dispersed set of paleopoles onto his simplest pole path. For example, rotations around vertical axes that are large but of opposite sense are implied in his Fig. 3 for the Mount Peyton diorite (pole 56) and the Mount Peyton granite (pole 85) and yet the older Botwood Group (poles 54 and 55) in the same geological setting shows negligible paleomagnetic evidence for such local rotation by comparison. The inconsistent pattern of implied rotation is not limited to Acadian intrusions from Newfoundland; the St. Stephen and the St. George plutons (poles 80 and 82 ) and the Cape Breton granite (poles CB2 and CB4) are other examples of data sets that would imply large rotations of contradictory sense within other regions.

\section{Concluding remarks}

It would be most exciting if some systematic age progression of paleolatitudes as proposed by Roy for the tectonically displaced terrains in the eastern Appalachians could be established. This would permit the development of improved models for the tectonic evolution of the Appalachians by the establishment of a paleogeographic framework to study possible interactions with other Paleozoic land masses. We agree with Roy that portions of the eastern Appalachians are likely to have been tectonically displaced (e.g., Kent and Opdyke 1978) but disagree that the displacement history suggested by Roy's analysis is either reasonable or supported by a straightforward interpretation of the geological and paleomagnetic data.

The SPPP analysis Roy presents does, however, further elucidate the anomalous nature of most paleomagnetic results obtained from Acadian intrusive rocks in terms of their tectonic implication. Although we described how these data are anomalous, we do not pretend to understand why. It is beyond the scope of this already lengthy reply to speculate on possible rock magnetic, geomagnetic, or other causes for the anomalous directions but we think a sufficient basis has been established to justify intensive research into what appears to be a perplexing yet important problem.

As a final point, we find that Roy's tacit acceptance of paleomagnetic data from igneous intrusions for his SPPP analysis is ironic in the perspective of the previous discussion of fold tests. Not only is supportive field evidence for the age of magnetization undocumented for these units, there is virtually no control on the amount of tilting involved since their emplacement. Implicit in his analysis is that post-emplacement tectonic tilting (rotation about a horizontal axis) is negligible, yet large tectonic rotations about local vertical axes are invoked to explain the scatter in paleopoles from these intrusions. If Roy persists in this view, he may at least also grant the possibility of the more modest rotations that we suggest contribute to the dispersion of the tilt-corrected site mean directions from the Hersey red beds and Eastport formation.

\section{Acknowledgment}

This research was supported by National Science Foundation grant EAR 80-07748.

Beales, F. W. Carracedos, J. C., and Strangway, D. W. 1974. Paleomagnetism and origin of Mississippi Valley-type ore deposits. Canadian Journal of Earth Sciences, 11, pp. 211-223. 
CORMIER, R. F. 1972. Radiometric ages of granitic rocks, Cape Breton Island, Nova Scotia. Canadian Journal of Earth Sciences, 9, pp. 1074-1086.

DeUTSCH, E. R., and RaO, K. V. 1970. Paleomagnetism of Ordovician sedimentary rocks from Bell Island, Newfoundland (abstr.). Eos, 51, p. 272.

1977. New paleomagnetic evidence fails to support rotation of western Newfoundland. Nature, 266, pp. 314318.

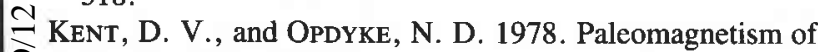
the Devonian Catskill red beds: evidence for motion of coastal New England - Canadian Maritime region relative to cratonic North America. Journal of Geophysical Research, 83, pp. 4441-4450.

1980. Paleomagnetism of Siluro-Devonian rocks from eastern Maine. Canadian Journal of Earth Sciences, 17, pp. $1653-1665$.

Kono, M. 1980. Statistics of paleomagnetic inclination data. Journal of Geophysical Research, 85, pp. 3878-3882.

LAPOINTE, P. L. 1979. Paleomagnetism and orogenic history of the Botwood Group and Mount Peyton batholith, Central Mobile Belt, Newfoundland. Canadian Journal of Earth Sciences, 16, pp. 866-876.

MACDONALD, W. D. 1980. Net tectonic rotation, apparent E. tectonic rotation, and the structural tilt correction in paleo- magnetic studies. Journal of Geophysical Research, 85, pp. 3659-3669.

RAO, K. V., and VAN DER Voo, R. 1980. Paleomagnetism of a Paleozoic anorthosite from the Appalachian Piedmont, northern Delaware: possible tectonic implications. Earth and Planetary Science Letters, 47, pp. 113-120.

Rao, K. V., Seguin, M. K., and Deutsch, E. R. 1981. Paleomagnetism of Siluro-Devonian and Cambrian granitic rocks from the Avalon zone in Cape Breton Island, Nova Scotia. Canadian Journal of Earth Sciences, 18, pp. 1187-1210.

RoY, J. L. 1972. A pattern of rupture of the eastern North American - western European paleoblock. Earth and Planetary Science Letters, 14, pp. 103-114.

Roy, J. L., and ANDERSON, P. 1981. An investigation of the remanence characteristics of three sedimentary units of the Silurian Mascarene Group of New Brunswick, Canada. Journal of Geophysical Research, 86, pp. 6351-6368.

WIEBE, R. A. 1972. Igneous and tectonic events in northeastern Cape Breton Island, Nova Scotia. Canadian Journal of Earth Sciences, 9, pp. 1262-1277.

YoRK, D. 1978. A formula describing both magnetic and isotopic blocking temperatures. Earth and Planetary Science Letters, 39, pp. 89-93. 